\title{
Technical-and-economic aspects of the analysis of the heating systems maintenance in the conditions of urban environment
}

\author{
Natalia Verstina ${ }^{1, *}$ and Evgeny Evseev ${ }^{2}$ \\ ${ }^{1}$ Moscow State University of Civil Engineering, Yaroslavskoe shosse, 26, Moscow, 129337, Russia \\ 2 Moscow Institute of Physics and Technology, Institutsky Lane, 9, Moscow region, \\ Dolgoprudny, 141700, Russia
}

\begin{abstract}
In the modern world one can notice considerable rates of the increase in quantity and size of the large cities which have received the general name reflecting their key characteristics - they are named megalopolises. The directions of the enhancement of the processes of the heating systems maintenance in the modern urban environment in its constant development are considered in the article. The author determines the directions of the technical-and-economic analysis of the maintenance of this type of facilities in the urban environment, which will allow filling the gap between the level of maintenance properties of the heating systems, demanded in the modern conditions, and the actual level. Some methodical provisions of carrying out the technical-and-economic analysis of the heating systems operation, which complex nature provides the objective assessment of the essential factors action during their functions completion within the urban environment, are suggested.
\end{abstract}

\section{Introduction}

Concentration of the population in large cities has reached such a level that near 10 percent of the population of our planet constantly live and work there while about 40 percent of world's population are concentrated in the urban environment as whole. Among the countries with the largest territory and the biggest population, Russia holds the 51th place in the world according to the urban saturation, owing to that the problems of the urban environment development are identified with the respect to the example of the large cities of our country with the great degree of reliability. The development of megalopolises brings new realities which are expressed as the emergence of new problem aspects of the urbanization including those providing the facilities of the population activity connected with energy resources [1-3].

Nowadays the providing consumers with energy resources is performed due to activities of the entities operating the city infrastructure facilities, such as engineering systems. Among such entities in modern Russian megalopolises there are the entities of centralized

\footnotetext{
"Corresponding author: verstina@mail.ru
} 
heating systems which in comparison with the decentralized heating systems of the facilities in smaller residential locations, gained the preferential development. In the large cities abroad (in the Scandinavian countries, such as Denmark, Norway, Sweden, Finland, and also in Canada), which climatic conditions are similar to the Russian conditions, heating supply on the basis of centralized transportation of energy resources from the combined plants heat and power supply and its distribution between consumers prevails.

The centralized heating systems in Russia formed by the entities of various scale making up $35 \%$ of the total consumption of cumulative energy consumption in our country is also the largest one in the world - more than $40 \%$ of the world centralized production and delivery of the heat energy is its share. At the same time, the technical-and-and economic aspects of activities of the entities of heating systems become the problem in the development process of the large cities and are exposed to criticism from consumers and city authorities (municipalities) as well. Nowadays it is stated, that in the structure of all the payments of the entities and the populations of the large cities for utilities fee (for heating and hot water supply, provided by the heating systems) makes about $50 \%$. That demonstrates the existence of obstacles in effective development of the modern cities, which needs the availability of financial resources and should be based on the rational organization of the urban environment structure, which is partly formed by heating systems.

Some research, devoted to this perspective, determined the key condition, which accumulates the technical and economic aspects of the heating systems operation in the modern cities, which represents ensuring energy saving within the processes of transportation and distribution of heat energy [4-6]. Cost analysis, concerning the losses of heat energy at the Russian heat supplying entities in the large cities, demonstrates that the greatest losses of heat energy are observed in the following proportions: at the consumer up to $30 \%$, during the transporting heat energy - up to $25 \%$, during the production - up to $22 \%$ of the total amount. At the same time losses of heat energy in the case of its transportation and distribution, tend to growth in the conditions of preserving traditional approaches to management of the heating systems operation and the lack of information required for its enhancement. Thus, the development of methodical provisions on carrying out the technical-and-economic analysis of the heating systems operation in the conditions of the urban environment in the sake of ensuring energy saving becomes urgent. The scale of the base considered in the research completed in Russian urban territories to some extent is unique, as the entities of the heat supply play the key role in the market of heat supply in Russia, making up more than $2 \%$ of GDP of our country.

\section{Methods}

As for the input conditions of the analysis of energy saving ensuring during the use of heating systems at the modern Russian entities of heat supply which number is about 20 thousand in the cities of various scale, according to some expert data, for the two-pipe calculation, about 175 thousand $\mathrm{km}$ from the total general extent the number of heating systems requiring repair makes up 50 thousand $\mathrm{km}$, that is the third part from the total heating systems extent. According to various experts 30 percent of the heating systems (on average) under maintenance by the Russian heat-supplying plants are out of standard service life. In the circumstances considerable funds are spent on the maintenance of lowquality and thus unreliable heating systems with actual thermal losses from 20 to $50 \%$ of heat in the winter and from 30 to $70 \%$ in the summer, with the heat carrier leakage exceeding the regulations of losses fixed in foreign countries. It represents significant risks for the urban environment - during 1 calendar year from 6 to 7 thousand cases of damages and failures of the heating systems leading to failures in providing consumers with heat energy are noted. Besides definite losses of heat energy and the heat carrier itself until the 
localization of defects are observed, and that does harm the city environment. During the consideration of this situation at the level of the separate heat supplying entity of the city it is noted that at least 10-15 percent of the heating systems under maintenance are subject to complete replacement, however, in every particular case the local decision is made and its generalization in scientific aspect is not possible yet. At the same time, due to the use of the evidence-based integrated approach to the analysis of technical-and-economic aspects of the heating systems maintenance in the conditions of the urban environment it is possible to reduce losses of heat energy by one third at list.

Formation of principle concepts for the analysis. Technical-and-economic aspects of the heating systems maintenance is based on the preliminary systematization of the conceptual framework, which is related with energy saving during the heating systems maintenance which needs to be treated as the integral component of the principle engineering procedure of the heat supplying entities, i.e. - transportation and distribution of heat among consumers [7]. In the conditions of Russia, Belarus, etc. the idea of "industrial safety" is applied for the facilities, which are especially dangerous for the urban environment. That is regulated by the special law which is concerned with the heating systems maintenance [8, 9]. This practice of establishment of especially strict requirements is out of practice in other countries therefore it is interesting to study the experience of the organization of heating systems maintenance in the conditions of the state control as well as the determination of the availability of additional opportunities of energy saving (or their absence).

The research demonstrated that the main approaches to the industrial safety regulation in the field of equipment under excessive pressure surveying are similar in the CIS countries. Moreover, the same approach to the technical issues of safety of facilities in the urban environment, are established in countries of the Eurasian Economic Union, such as: Russia, Belarus and Kazakhstan (except for the fact that in Kazakhstan heating systems are excluded from the list of dangerous industrial facilities). The roles of the state and the heat supplying entities, concerning ensuring the industrial safety in other countries are different a little. The greatest amount of countries with centralized heating systems is concentrated in Europe, where they make up 85 percent from the total amount. The main document for these countries is the directive on the use of the working equipment $[10,11]$. In each EU country, there is its own option of the directive performance: in Great Britain they use the law PUWER, while in France - Décret $n{ }^{\circ}$ 93-40 is applied. The practice in Germany and Austria is different a little: they have their own rules for the industrial safety: and the Act of an occupational health and safe engineering respectively [12]. At the same time one important feature is noted both in the conditions of strict state regulation for the ensuring of industrial safety and in in case of its absence - in each case the heat supplying entities or the external expert organization can independently appoint any monitoring procedure techniques, the frequency of surveying, etc. within the analysis of the heating systems maintenance in the conditions of the urban environment.

In this regard the idea of "technical performance of the heating system" gains the principle importance, as it creates all the system of concepts for carrying out the analysis as well as their treatment in the context of the main process of ensuring energy saving, i.e. control of the heating system performance, which is first of all aimed on the fulfillment of requirements of the legislation of the country regarding the safety of engineering systems in the urban environment. In the Russian conditions the determination of the concept "technical performance of the heating systems", is carried out according to the regulating document of the Russian Federation - state standard specification 20911-89, establishing the terms and determinations applied in science and technology in the field of technical diagnosing and control of the performance of facilities. This document defines "technical performance of a facility" as the condition which is characterized at a given time, under certain conditions of the external environment and the parameter values, established by 
technical documentation for the facility. The development of the approach to carrying out the analysis of technical-and-economic aspects of the heating system maintenance required additional identification of the last part of the definition - "the parameters set by technical documents for a facility".

Methodologically three key technical aspects of general nature, preceding the analysis of heating systems maintenance, were pointed out. According to the accepted order of construction in the urban environment, the completion of construction-and-installation works on creating the engineering system, which are carried out according to the specification on designing based on the standard requirements for this type of facilities 124.13330.2012 [13]. As the version of determination, modified for the analysis purposes, the following one is suggested: "Technical performance of heating systems is such a performance, which is estimated at the given time, under certain conditions of the external environment, by the parameter values, established according to the requirements of standards for designing, installing and maintenance of heating systems in the conditions of the urban environment". Obligatory fixing of the time point, at which the performance is analyzed, directly follows this determination. In this regard, within the analysis in the sake of comparability the results of control of the heating systems under maintenance performance it is necessary to regulate the terms of its carrying out and strictly follow them during a long surveying period irrespective of the analysis purposes.

The second technical aspect of the analysis are environmental conditions of the heating systems maintenance in the urban environment. The analysis shown the specifics of the heating systems maintenance in comparison with other facilities in the urban environment: the influence of the external environment, considered in dynamics, acts as the reason of gradual emergence of retreats in the performance of engineering system elements from the set parameters during the maintenance. The main reason for the emergence of damages of heating systems which are to be excluded for energy saving is the existence of the corrosion processes, which eventually lead to failures of metal elements of heating systems (Figure 1).

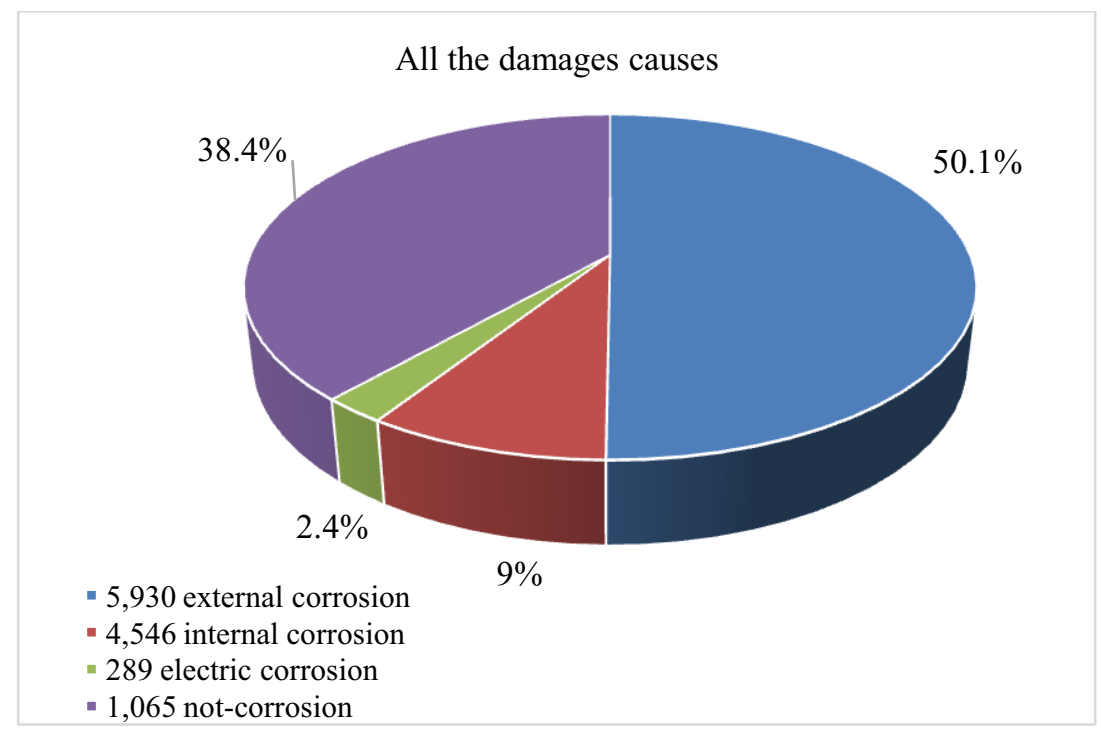

Fig. 1. Distribution of the refusals of the heating systems under maintenance in the urban environment according their causes during 2010 - 2015 (the example of Moscow).

Therefore, it becomes obvious that for improvement of the heating systems maintenance in the conditions of the urban environment it is important not only to obtain some control 
data of the performance at the certain time point, but also constantly accumulate retrospective data on the performance of the external environment of the heating system in dynamics. This term will provide the required objectivity of the assessment of the heating system technical performance in the conditions of the urban environment, which, in turn, is subject to changes too.

The third technical aspect of the analysis are the parameters, set by requirements of standards for design, installing and maintenance of heating systems. Their definition has to be provided during the surveying procedure for the heating system performance, so there appear the question of how shall we determine the required parameters taking into account the requirements of standards, and how to characterize the heating systems maintenance basing on these parameters in the conditions of the urban environment, the subsequent quantitative assessment following. For the decision the identification of the following concept was carried out: "the characteristic of the technical performance of the heating systems". The main condition for the formulation of this definition is the opportunity to identify the subject performance unambiguously. The following definition is suggested: "The characteristic of the heating system technical performance is the list of the quantitative and qualitative parameters of the heating system under maintenance in the conditions of the urban environment recorded at the given time, under certain conditions of the external environment of the engineering system".

Methodologically we have also pointed out some economic aspects of the analysis of the heating systems maintenance in the conditions of the urban environment as the use of the research results only at the level of technical systems does not allow receiving the unambiguous decision for the choice the control method for technical performance of the engineering system, as well as the choice of the tool base for the certain control methods. For the implementation of that the authors used the methodical provision which was not practically considered before within the analysis of the heating systems under maintenance: within the choice of methods of non-destructive control it is necessary not only to consider this question in relation to the certain sites of the heating systems, but also to carry out the analysis in the scales of the heating system industry as whole with all the variety of the engineering systems, which differ in constructive features and in the maintenance terms. It is obvious, this provision is also developing with the matter of the availability of resources for the surveying procedure at the heat supplying plant. The analysis is to be completed with the determination of financing tactics for the activities on ensuring energy saving during transportation and distribution of heat.

\section{Results}

In the presence of enough developments on the analysis of technical performance of the heating systems under maintenance and technical means for providing Russian specialists keep in the centre of their attention the debatable question concerning the advantages and disadvantages of two diametrical approaches to diagnostics: the first one is based on nondestructive control methods while the second one is based on carrying out the hydraulic testing (HT) which appeared and keep their popularity in the large cities first of all.

The matter can be reasonably solved by the means of full or partial refusal of HT of the heating systems. The technical aspects can be summarized as following - replacement of the centralized HT by the methods of non-destructive control and local pressure of the heating systems sites with the application of stationary and mobile pump stations. The most progressive methods of in-line diagnostics are not able to give $100 \%$ of the comprehension of the actual performance of the engineering system and its working resource. It is necessary to carry out the whole complex of diagnostic measures with the use of other types of non-destructive control (infrared diagnostics, acoustic and correlation diagnostics, etc.). 
The reliability of the available methods of in-line diagnostics is at the level of $75-80 \%$ which is 1.5-2 times higher, than the reliability of other methods of non-destructive control. Basing on such indicators the improvement of the methods of in-line diagnostics in combination with the methods of non-destructive control, aimed on the replacement of HT, takes place in the practice of the heating system maintenance. The technical conditions of the external environment are defined in the article (Table 1).

Table 1. Environmental conditions, admissible for the use of devices for non-destructive control.

\begin{tabular}{|c|c|c|c|c|c|}
\hline $\begin{array}{c}\text { Place of the } \\
\text { device } \\
\text { operation }\end{array}$ & $\begin{array}{c}\text { Air } \\
\text { temperature, }{ }^{\circ} \mathrm{C}\end{array}$ & $\begin{array}{c}\text { Air } \\
\text { humidity, } \\
\%\end{array}$ & $\begin{array}{c}\text { Heat carrier } \\
\text { temperature, }{ }^{\circ} \mathrm{C}\end{array}$ & $\begin{array}{c}\text { Pipe surface } \\
\text { temperature, }{ }^{\circ} \mathrm{C}\end{array}$ & $\begin{array}{c}\text { Snow } \\
\text { layer }\end{array}$ \\
\hline $\begin{array}{c}\text { Access point } \\
\text { (chamber, } \\
\text { cellar, } \\
\text { collector) }\end{array}$ & to 35 & to $90 \%$ & to $100^{\circ} \mathrm{C}$ & to $100^{\circ} \mathrm{C}$ & - \\
\hline $\begin{array}{c}\text { In the pipeline } \\
\text { with water }\end{array}$ & - & - & to $70^{\circ} \mathrm{C}$ & & - \\
\hline $\begin{array}{c}\text { In the } \\
\text { pipeline } \\
\text { without water }\end{array}$ & to $50^{\circ} \mathrm{C}$ & to $90 \%$ & - & - & - \\
\hline $\begin{array}{c}\text { On the land } \\
\text { surface over the } \\
\text { route }\end{array}$ & $\begin{array}{c}\text { from }+35 \\
\text { to }-20^{\circ} \mathrm{C}\end{array}$ & to $90 \%$ & - & & $\begin{array}{c}\text { to } 40 \\
\text { cm. }\end{array}$ \\
\hline
\end{tabular}

It is established that replacement is especially urgent on the heating systems which have served standard service life (more than 25 years), on the sites which are periodically waterlogged by ground waters or the subject of internal and external corrosion during the use including quarter pipelines of the heating systems with diameter (D)to $200 \mathrm{of} \mathrm{mm}$. In this regard the research reference point was accepted: the determination of the possibility of implementation of complete or partial refusal of HT of the pipelines of the heating systems in the conditions of the urban environment on the basis of the analysis of technical-andeconomic aspects, on the basis of reduction of the periods of shutdown of consumers, on the basis of identification of certain restrictions of standard, technical and technological, economic nature.

The Russian standard requirements provide carrying out of HT in three situations: during the heating systems maintenance - as the finishing element of annual production cycle, as well as in two other situations connected with the works on improvement of properties of heating systems according to modern requirements of the urban environment. During the research these provisions were concretized. According to the Russian regulating documents during the use all the heating systems should be the subject to testing for durability and density in order to detect any of defects not later, than in two weeks after the end of a heating season (item 6.2.13). According to the item 169 [14] hydraulic testing for the purpose of testing the density and durability of the equipment under pressure are also carry out:

1. after reconstruction (modernization), repair of the equipment with application of welding of the elements working under pressure;

2. during engineering certifications and technical diagnosing.

Along with the determination of situations for carrying out HT, technical parameters are identified, including: the minimum size of trial pressure during the hydraulic testing of steam and hot water pipelines, their blocks and separate elements shall constitute 1.25 of the working pressure, and not less than $0.2 \mathrm{MPa}$. The armature and shaped details of pipelines should treated by the means of HT with the trial pressure according to technological documents. The maximum value of the trial pressure is established by 
calculations on durability of pipelines. The value of trial pressure (which is between admissible maximum and minimum) should provide the greatest detectability of defects of the heating systems or their elements, which are subjects to HT. Regulating documents analysis stated that during engineering certification of the pipeline replacement of HT with two types of control (radio-and-graphical and ultrasonic) in cases of quality control of connecting welded joint of the heating systems with the pipeline of the highway under maintenance, is allowed, as well as in case of control of two or less one-piece welded connections executed in case of repair of the item 406 [15].

The experimental data prove that HT of heating systems (particularly) in the cities and megalopolises results in the great number of the "rushes" under pressure, which demonstrate the existence of risks of thermal losses during the heating period. The low level of damages during the winter season is provided generally due to detection of critical defects during the summer period. At the same time the important technical aspect is obvious - it is impossible to provide the long period of reliable heating systems maintenance in the urban environment by the means of HT.

Despite the annual increase in amount of works on repairs, modernization and reconstruction of the heating systems, aimed on providing their proper properties, the dynamics of the growth of damageability of the heating systems "average about the country" remains. During HT of the heating systems literary all the pipelines and equipment, including rather new sites of the heating systems (from 1 to 10 years under maintenance) are exposed to the excessive pressure. The sites of the heating systems, shifted during repairs in the previous years, along with the sites which had served standard useful life (25 years and more), pass single HT without gradation of pipelines according to maintenance time, i.e. the single approach to new and old pipelines is used. This "unity" of HT, forced technologically, also caused some negative affects on certain sites of pipelines of smaller diameters: thus the pressure of 2.5-3.0 MPa $(25-30 \mathrm{kgf} / \mathrm{cm} 2)$ will be required for the sites of the heating systems with wall thickness under $1 \mathrm{~mm}$, small diameters of pipes require considerably greater pressure.

The results of the analysis completed, according to the authors, prove that there is a number of positive technical effects of centralized HT, but disadvantages are obvious too. In the economic aspect the identification of sites with damages and the subsequent repair requires considerable additional labour and material expenses, which are not always justified. Besides, annual HT are followed by lots of disconnections of facilities of the urban environment from hot water supply, mass claims from consumers because of its low quality in case of the termination and renewal of water supply, and, as a result, the refusal of payment, legal claims, penalties, etc., the economic and reputation factors connected with that play their considerable role.

Resuming the experience of HT, completed in this research allows to define the directions, considering which makes possible to formulate the conditions for the refusal of HT. The most popular expert belief is that non-destructive methods have to provide $100 \%$ control of the pipelines surface regarding their failures. Let's expand that by the results of our research. During replacing HT with nondestructive control methods it is necessary to carry out control of thickness of walls, the intense deformed states, strength characteristics of metal of the heating systems. Technologically it is possible to provide $100 \%$ of continuous thickness test for the sites of the heating system only by the means of intra pipe methods of diagnostics either on the base of ultrasonic technology, or on the base of magnetic control (MC).

For the parts of the heating system 20 or less meters long continuous control for the identification of defective zones of the pipeline can be provided by the technology of longwave control (MsS3030R of the USA, Wavemaker G3 England), or acoustic issue (making it possible to change the pressure in the heating system within 1 bar.) The complex 
diagnostics with the use of integrated control methods (based on the technologies of acoustic tomography (AT), contactless magnetic diagnostics (CMD), acoustic issue, longwave control) followed by local ultrasonic control in the zones with revealed defects also allows confirming the existence or absence of critical corrosion defects with rather accurately. Continuous identification of critical tension of metal during maintenance is only provided only non-destructive methods based on AT, or BMD. The special set of the methods used instead of HT is to be chosen according to technical features of the site or several sites of the heating systems and technical restrictions for the use of this or that method of nondestructive control.

We believe, considering that in the modern urban environment it is necessary to fill the gap between the demanded level of properties of the heating systems under maintenance and the actual level, the identification of the specific characteristics of non-destructive control methods represents a rather "narrow" vision of the solution of the question just in the technical aspect.

It is necessary to provide a "broader" approach according to the results of nondestructive control of local repair including the elimination of corrosion factors, acting on the surveyed site of the heating system, and also the factors causing the critical intense-anddeformed performance. The range of traditional control can be also expanded by the organization of fixed monitoring of the technical performance of the heating system with making a retrospective database. The results of such a monitoring will allow performing reliable forecasting of the heating system performance, in scales of the heat supplying plant as whole.

Because of the lack of unambiguous opinion of the specialists on the choice of the best means of control of technical performance of the heating systems, basing on the technical aspects of the analysis of their maintenance, in this research the set of the arguments considered for the solution of this question is expanded and some economic aspects are considered [16]. Two directions of the analysis were distinguished. The first direction is the choice of the site with certain constructive characteristics and fixed useful life, under the methods, alternative to HT, such as non-destructive control, with certain characteristics (the cost of control, accuracy of detection of damages). The choice is suggested to be held on the basis of comparison of the amount of total expenses (S) taking into account the probabilities of events:

$$
S=\lambda * \iota * S_{\text {failure }} *\left(1-p_{m}\right)+S_{\text {met hod }}+S_{\text {hole }} * q_{m}
$$

Where $\mathrm{i}$ - failure rate at the site $\left(1 / \mathrm{km}\right.$./year); 1 - length of the site $(\mathrm{m}) ; \mathrm{S}_{\text {failure }}$ - the cost of losses at failure of the site taking into account losses from the necessary compensations;pm - probability of identification of the existing defects by the method; $\mathrm{S}_{\text {method }}$ - the cost of inspection of the site by the method of non-destructive control; $\mathrm{S}_{\text {hole }}$ hole device cost; $\mathrm{q}_{\mathrm{m}}$ - the probability of identification of the absent method by the compared defect.

The dependences of the monitoring procedure cost in case of the use a certain method (S) on the work $\left(1 * \mathrm{i} * \mathrm{~S}_{\text {failure }}\right)$ were considered within the research. Depending on the amount of losses the method with the smallest value (S) was chosen.

It is suggested to formulate the task of searching for the required method of nondestructive control as follows: for the set site and useful life from the moment of input of the site into maintenance, it is required to determine the method or group of methods of non-destructive control which application is most effective nowadays. In case of the choice of the required method of non-destructive control the use of function of paired comparison of the methods, chosen for the analysis, is necessary. Let's define that as follows: for two methods of diagnostics D1 and D2 the three following functions exist, if method D1 is more efficient, than method D2, M(D1,D2) $>0$, if method D1 is less efficient, than method 
$\mathrm{D} 2$ and $\mathrm{M}(\mathrm{D} 1, \mathrm{D} 2)=0$, if methods $\mathrm{D} 1 \mathrm{uD} 2$ are equally efficient. This function makes it possible to carry out sorting of methods of non-destructive control for the analyzed site of the heating system under maintenance, which is the sites of heating economy of a certain heat supplying facility, and to choose the best of them.

Let's enter the following designation: for diagnostics method $\mathrm{Dj}$ we designate

$S_{y}^{j}(t)=\frac{S\left(t+\lambda^{j}\right)-S(t)}{\lambda^{j}} \quad$ where $\lambda$ is the term of extension of the method of diagnostics Dj. i.e. $S_{y}^{j}(t)$ is the amount of specific maintenance costs for the site with the use of the method of diagnostics $\mathrm{Dj}$, calculated not for all the service life, but for the time interval, corresponding to the term of extension of the method of diagnostics $\mathrm{Dj}$, since $\mathrm{t}$.

Let's set the function M(D1,D2) as follows.

This function completely meets the requires of the definition of the function of paired comparison of the methods of diagnostics. In fact, if $\mathrm{M}(\mathrm{D} 1, \mathrm{D} 2)<0$, then $\mathrm{S}_{\mathrm{y}}^{1}<\mathrm{S}_{\mathrm{y}}^{2}$ and method D1 is more effective than method D2, as less funds are required for the site, when using the method of diagnostics D1. Also $1 / \mathrm{S}_{\mathrm{y}}^{\mathrm{j}}$ for the method of diagnostics Djcan be used as integrated technical-and-economic criterion of efficiency: the more this value - the effective is the considered method of non-destructive control. The analysis results prove that the choice of a required method of diagnostics directly depends on the site performance. The situation in which the application of different methods of non-destructive control will be the most effective at various moments of its lifecycle is quite possible the site service life through.

The second direction represents sufficient disaggregation of the analysis of methods of non-destructive control of technical performance of the heating systems under maintenance; it is connected with studying of expenses for implementation of a certain method of nondestructive control.

The analysis of technical means of non-destructive control is based on the comparison of the result of the control essential to the safety of the urban environment and the total expenses, connected with the use of a certain technical tool of control as the result achieved, The change of a measure value of reliability of the heating systems maintenance, at the expense of the prevention of the emergencies revealed during control can be accepted. As a part of costs for technical means of control not only the cost of direct control and the subsequent processes of data acquisition, but also the losses connected with possible emergence of failures in the use of heating systems and other consequences of insufficient accuracy of a method of non-destructive control shall be considered.

In general form the efficiency of technical means of control can be presented with the help of the integrated indicator of efficiency $Q_{j}$, which characterizes the ratio of the measure of $G_{j}$ of the compliance of the analyzed means, the objective and total expenses $\ni_{\Sigma j}$ :

$$
\mathrm{Q}_{\mathrm{j}}=\mathrm{G}_{\mathrm{j}} / \ni_{\Sigma j}
$$

For the calculation of the size $\mathrm{G}_{\mathrm{j}}$ as the $\Delta \mathrm{H}_{\mathrm{j}}$ change of the probability of failures during the use with regard to the reference value of $\mathrm{H}_{0}$ it is necessary to know: types of the defects leading to failures of concrete elements of the heating systems $\mathrm{D}_{\mathrm{ki}}$ which can be detected during the use, and their potential possibility $\mathrm{PA}_{\mathrm{ki}}$; distributions of $\mathrm{f}_{\mathrm{ki}}(\mathrm{m})$ of the quantity (m) of defects $D_{k i}$ at the facility; probabilities $P_{b p}\left(\frac{B_{k i}}{M_{t}}\right)$ of detection of defects $D_{k i}$ with the help of compared variants of methods of non-destructive control $\mathrm{M}_{\mathrm{t}}$ used by the heat supplying plants. 


\section{Discussion}

In some cases of the Russian practice it is difficult to prove experimentally the full range of quantitative indicators for the complete calculation, even despite the large volume of statistics of failures of the heating system. The main reason is that so far there is no systematic collection of this type of data, their verification and generalization. The attempts of forming of statistical materials carried out by authors confirmed the initial hypothesis of lack of the possibility of full statistical data acquisition, therefore it is suggested to differentiate the situation of assessment and to consider alternative options of data acquisition.

In practice of the choice of technical means of non-destructive control one or several situations within the provided approach are possible [17]. Depending on the availability of experimental data there the options of determination of parameters, given below, which quantitative values are determined by the conditions of the specific heat supplying plant:

1. Definite distribution of $\mathrm{f}_{\mathrm{ki}}(\mathrm{m})$ is unknown $\mathrm{f}_{\mathrm{ki}}(\mathrm{m})$ can be calculated according to two values $f_{k i}(0)$ and $f_{k i}(m)$, where $m$ is the most probable quantity of defects (failures) of $\mathrm{D}_{\mathrm{ki}}$ for a certain type of the heating system structure.

2. Exact values of potential possibility of defects $P\left(A_{k i}\right)$ are unknown, but the coefficients of danger $r$ are known $A_{k i}$ is replaced with the approximate values $P * A_{k i}$ :

$$
\mathrm{P} * \mathrm{~A}_{\mathrm{ki}}=\mathrm{P}^{*}\left(\mathrm{~A}_{\mathrm{m}}\right) \mathrm{r}_{\mathrm{k}} / \mathrm{r}_{\max },
$$

Where $r_{k}$ is the value of coefficient of danger for the defects of $D_{k i} ; r_{\max }$ - is the same coefficient for defect (failure) with the maximum potential danger of $\mathrm{P}^{*}\left(\mathrm{~A}_{\mathrm{ki}}\right)$.

3. $P\left(A_{\mathrm{ki}}\right)$ and $\mathrm{r}_{\mathrm{ki}}$ are unknown; all the defects (failures) are distributed into: admissible and inadmissible. $P\left(A_{d}\right)=0$, is determined first, and then $P\left(A_{n}\right) \approx 1$ is attributed.

4. Lack of value of probabilities of $P_{b p}\left(\frac{B_{k i}}{M_{t}}\right)$ for the considered and similar facilities. Then value $\mathrm{P}_{\mathrm{bp}}$ for each method should be established experimentally.

Total expenses $E_{\sum j}$ are determined with the analyzed technical tool of the nondestructive control $G_{j}$ by the amount of control expenses $\left(E_{k j}\right)$, the auxiliary processes accompanying the control $\left(E_{b j}\right)$, and losses owing to the insufficient accuracy of the measurements completed $\left(\mathrm{E}_{\mathrm{nj}}\right)$, i.e.

$$
E_{\sum j}=E_{k j}+E_{b j}+E_{p j} .
$$

Losses $\mathrm{E}_{\mathrm{pj}}$ are considered in special cases because of errors of definition of technical condition of the facility which come down to identification by control of unacceptable defects of the heating system structures while actually there are admissible defects. At the same time the probability of "rerejection" is determined by the probability of formation of such defects in the heating system under maintenance. There can be also errors of other character caused by imperfection of technical means of non-destructive control as a result of which defects on the controlled site of the heating system which actually are absent could be identified.

The research has proved that the integrated indicator of efficiency $Q_{j}$ can be used for the solution of the following situations of the choice of methods of non-destructive control:

1. Emergency at the site of heating system is followed by losses incomparable to losses from "rerejection", i.e. some acceptable value $\mathrm{E}_{\Sigma_{*}^{*}}$ is set. In this case $\mathrm{E}_{\mathrm{n}}$ is unknown as the amount of losses is unknown. The decision is the maximization of technical efficiency in case of limited expenses 


$$
\begin{gathered}
\mathrm{E}_{\Sigma}=\mathrm{E}_{\mathrm{\kappa}}+E_{\mathrm{B}}+\mathrm{E}_{\mathrm{p}} ; \Delta H_{\mathrm{p}}=\max \Delta H, \\
\left(\mathrm{E}_{\mathrm{K}}+E_{\mathrm{B}}+\mathrm{E}_{\mathrm{p}}\right)_{\mathrm{r}} \leq \mathrm{E}_{\Sigma *}
\end{gathered}
$$

2. Due to the particular liability of certain sites of the heating systems some minimum value is set $H_{j}^{*}$, probabilities of trouble-free maintenance of engineering system. Than expenses $E_{n}$ are constant and the problem is solved by minimization of the function

$$
\mathrm{E}_{\Sigma j}=\mathrm{E}_{\mathrm{\kappa j}}+E_{\mathrm{Bj}}+\mathrm{E}_{\mathrm{pj}}
$$

if technical efficiency is not below the set level:

$$
\begin{gathered}
\mathrm{E}_{\Sigma \mathrm{r}}=\min \left(\mathrm{E}_{\mathrm{K}}+E_{\mathrm{B}}+\mathrm{E}_{\mathrm{p}}\right) \\
\Delta \mathrm{H}_{\mathrm{r}} \geq H_{j}-H_{o}
\end{gathered}
$$

3. Losses $E_{p}$ from emergency at the heating systems under maintenance are commensurable with losses $E_{r}$ from "rerejection" of engineering system. Among methods of non-destructive control of a certain group with equal or close minimum values $\quad R_{j}=\mathrm{E}_{\Sigma j}+\mathrm{E}_{r j}$ оптимальнымбудетметодсмаксимальнымзначением $\Delta H_{j}$. Thus:

$$
\begin{array}{r}
R_{\mathrm{r}}=\min \left(\mathrm{E}_{\Sigma}+\mathrm{E}_{\mathrm{r}}\right) \\
\Delta \mathrm{H}_{\mathrm{r}}=\max \Delta H, R \approx R_{\mathrm{r}} .
\end{array}
$$

In practice during calculations [18] two or more methods of non-destructive control can meet the stated conditions. Then in order to choose the optimal method it is necessary to use additional expert evaluations. The aforesaid results of analysis of the heating systems is very important in the economic aspect for filling the gap between the demanded level of the maintenance properties of the heating system in modern conditions and the actual level on the basis of methods of non-destructive control. But at the same time in scales of the heating economy of the heat supplying facility the concentration of enough financial resources is necessary for ensuring financing measures for the achievement of reducing cumulative accelerated depreciation [19-21]. This requirement along with the methods of non-destructive control, chosen according to technical and economic parameters will provide desirable effect in scales of the urban environment as whole.

\section{Conclusions}

So far there were no attempts to undertake the analysis of $t$ functioning of the heating systems as a part of the urban environment. Development of the urbanization processes along with the growth of number and the sizes of cities caused the need of the analysis of the heating systems maintenance, aimed on searching for any directions of their enhancement, which would allow to reduce and then to liquidate the gap between the level maintenance properties of the heating systems, demanded in modern conditions and the actual level. This perspective was studied on the example of Russian heat supplying facilities, mostly united in systems of centralized heat supply, which cumulative extent is much greater than the extent of similar systems in other countries. Important message of the analysis the heating systems maintenance in the urban environment became both technical, and economic aspects of the analysis for which we can suggest some methodical provisions, which complex nature provides objective assessment of the essential factors, 
influencing on the accomplishment the functions by the engineering systems. During the analysis it was revealed that the first group of factors of maintenance (technical) are prior and should be considered first of all for the choice of methods of control technical performance of heating systems with great accuracy. At the same time the second group of factors (economic) can provide a new foreshortening of the considered problems decision, transferring it from "plane" perception such as replacement of one technology of control (destroying) to another (non-destructive) within the technical system of the heat supplying facilities into "volume" vision of the directions of the enhancement of the heating systems at a higher level of the decisions made within the organizational activities for diagnostics for all the heating industry.

\section{References}

1. District Heating Conference 2015: Heat Networks: Making affordable, low-carbon heat a reality (High School Yards, Edinburgh, 2015)

2. Sino-Danish district heating conference and knowledge sharing seminar (DEA-NECC, Copenhagen, 2016)

3. E. Stein, N. Taskaeva, E.Chibisova, Procedia Engineering 165, 1410-1416 (2016)

4. T.Blinova, MATEC 73, 07023 (2016)

5. N.G. Verstina, T.S. Meshcheryakova, Biosciences Biotechnology Research Asia1, 122 (2015)

6. Ir. Polyakova, E. Vasilyeva, Procedia Engineering 165, 1380-1387 (2016)

7. N. Verstina, MATEC , 73, 07022 (2016)

8. M.J. Tyre,RES POLICY 1(20), 57-76.(1991)

9. A. Pimenova, S. Kuzmina, N.Morozova, A. Mottaeva, MATEC 73, 07018 (2016)

10. Ensuring of safety of the working equipment maintenance. UK Standard (PUWER, London, 2016)

11. A. Mottaeva, MATEC , 73, 07020 (2016)

12. European Parliament and Council, Official journal 181, 0001-0055(2016)

13. Russian StandardSP 124.13330.2012

14. Rules of Industrial Safety of Dangerous Industrial Facilities, which Use Equipment, Working under excessive pressure (Ministry of Justice of the Russian Federation, Moscow, 2014)

15. N.G. Verstina, E.M. Akimova, T.G. Blinova, Real estate: economy, management3, 4247 (2015)

16. A.A. Krygin, Automatic equipment and telemechanics9, 83-102 (2010)

17. T.A. Verminskaya, V.Sh. Zinatullin, A.V. Kukhta, I.V. Rubtsov, E.Yu. Chibisova, Almanach of modern science and education7,37-39 (2008)

18. R. Dylewski, J. Adamczyk, Energy and Buildings 54, 88-95(2016)

19. S. V. Korniyenko, N. I. Vatin, A. S. Gorshkov, Magazine of Civil Engineering, 64, 1025, (2016), DOI 10.5862/MCE.64.2

20. R. Alihodzic, V. Murgul, N. Vatin, Applied Mechanics and Materials, 680, 494-498, (2014), DOI 10.4028/www.scientific.net/AMM.680.494

21. M. Penić, N. Vatin, V. Murgul, Applied Mechanics and Materials, 680, 534-538, (2014),DOI 10.4028/www.scientific.net/AMM.680.534 